\title{
Exhalation flow and pressure-controlled reservoir collection of exhaled nitric oxide for remote and delayed analysis
}

\author{
P Paredi, S Loukides, S Ward, D Cramer, M Spicer, S A Kharitonov, P J Barnes
}

\begin{abstract}
Background-Expiratory flow rate, soft palate closure, and dead space air may influence exhaled levels of nitric oxide (NO). These factors have not been evaluated in the reservoir collection of NO. Methods-Exhaled NO was collected into a reservoir during a single flow and pressure controlled exhalation.

Results-NO collected in a reservoir containing silica gel was stable for 24 hours. Nasally delivered $4.8 \%$ argon measured by mass spectrometry did not contaminate exhaled argon levels $(0.1(0.02) \%)$ in five volunteers during exhalation against a resistance (10 (0.5) $\left.\mathrm{cmH}_{2} \mathrm{O}\right)$, hence proving an effective soft palate closure. Exhaled NO in the reservoir was $11(0.2) \mathrm{ppb}$, $8.6(0.1)$ ppb, $7.1(0.6)$ ppb, and $6.6(0.4)$ ppb in five normal subjects and 48.3 (18) ppb, 20.3 (12) ppb, 16.9 (0.3) ppb and 10.1 (0.4) ppb in 10 asthmatic subjects at four studied expiratory flows (5-6, 7-8, 10-11, and $12-131 / \mathrm{min}$, respectively), with NO levels equal to direct measurement (7.3 (0.5) ppb and $17.4(0.5)$ ppb for normal and asthmatic subjects respectively, p<0.05) at the flow rate $10-111 / \mathrm{min}$. Elimination of dead space proved necessary to provide NO levels comparable to the direct measurement. Exhaled NO collected into the reservoir without dead space during flow controlled exhalation against mild resistance provided close agreement (mean (SD) difference $\mathbf{- 0 . 2 1}$ $(0.68)$, coefficient of variation $4.58 \%$ ) with direct measurement in 74 patients (NO range 1-69 ppb).

Conclusions-Flow and pressure controlled collection of exhaled NO into a reservoir with silica gel provides values identical to the direct measurement and may be used to monitor asthma at home and where analysers are not on site.

(Thorax 1998;53:775-779)
\end{abstract}

Keywords: exhaled nitric oxide; reservoir collection

The measurement of exhaled nitric oxide (NO) has excited considerable interest as it may provide a simple non-invasive means for measuring airway or pulmonary inflammation. ${ }^{1-4}$ There are three main approaches to the measurement of exhaled NO: (1) single slow exhalation manoeuvre into a chemiluminescence analyser (direct method) ${ }^{5}{ }^{6} ;(2)$ sampling into a mixing chamber at the expiratory side of a mouthpiece during tidal breathing ${ }^{7}$; and (3) collection of exhaled air into a reservoir during tidal breathing or single exhalation with analysis thereafter. The latter has been used in a few studies ${ }^{7-10}$ but in none of them have the authors evaluated the combined effect of expiratory flow, mouth pressure during exhalation, and elimination of dead space on the final NO level in the reservoir. Such factors are of primary importance in the evaluation of exhaled NO. ${ }^{5}$

Considering the increasing interest in the use of exhaled NO in the evaluation and home monitoring of lung diseases such as asthma, ${ }^{12}$ COPD,${ }^{11}$ bronchiectasis, ${ }^{12}$ and cystic fibrosis $^{1314}$ in both adults and children, we aimed to develop a new method for collection of exhaled NO into a reservoir during a single exhalation, allowing collection of exhaled NO when a conventional analyser is not available on site. We have studied the effect of expiratory flow, soft palate closure, and elimination of dead space air on exhaled NO collected into a reservoir in order to compare this technique direct measurements.

\section{Methods}

PORTABLE DEVICE FOR EXHALED AIR COLLECTION AND EXHALED NO MEASUREMENTS

A schematic diagram of the collecting device is provided in fig 1. A fixed flow restriction (mouthpiece diameter $=2.7 \mathrm{~cm}$, restriction diameter $=5 \mathrm{~mm}$ ) was introduced to increase pressure in the mouth up to $10 \mathrm{~cm} \mathrm{H}_{2} \mathrm{O}$ which is effective in closing the soft palate ${ }^{615}$ and isolating the nasopharynx. An indication of exhalation flow was achieved by a mouthpiece pressure gauge calibrated for flow to provide visual guidance for the subjects to maintain a constant flow rate. A three way valve open to the atmosphere during the first part of the manoeuvre was used to discard the first portion of exhaled air contaminated with ambient and nasal NO. The time needed to wash out the dead space $(t)$ was estimated to be $1-2 \mathrm{~s}(t=$ dead space volume/exhalation flow where dead space was calculated as weight (lb) + age in years, and exhalation flow was $10-11 \mathrm{l} / \mathrm{min}){ }^{16}$ Silica gel was used to prevent the condensation of vapour ${ }^{1017}$ in the reservoir. The collapsible reservoir (David S. Smith Liquid Packaging, type 5LMA 115) had an inner polyethylene layer which does not affect NO levels. ${ }^{9} 10$

Exhaled NO was collected into a collapsible reservoir during a single exhalation from total lung capacity to residual volume at a constant flow $(10-11 \mathrm{l} / \mathrm{min})$. The air in the dead space was discarded in the atmosphere by the valve. 


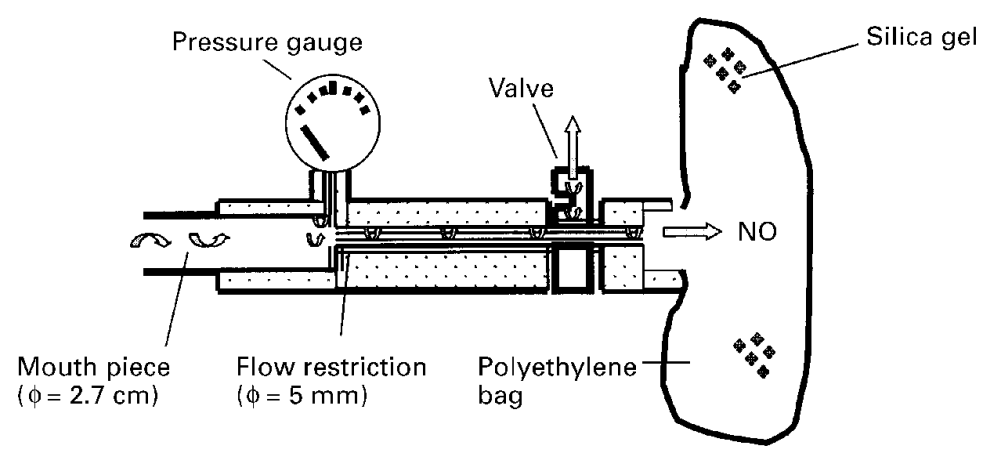

Figure 1 Schematic diagram of the portable equipment for collection of exhaled NO. The arrows indicate the direction of air flow. The three way valve is in the closed position for reservoir collection of exhaled breath.

The reservoir was later connected to a chemiluminescence analyser (LR2000, Logan Research, Rochester, UK) and sampled (sampling rate $250 \mathrm{ml} / \mathrm{min}$ ) for $\mathrm{NO}$ content.

DIRECT EXHALED NO MEASUREMENT

Exhaled NO was measured by the same chemiluminescence analyser with sensitivity from 1 part per billion (ppb) to $5000 \mathrm{ppb}$ of $\mathrm{NO}$, accuracy $\pm 0.3 \mathrm{ppb}$ and response time of $<2$ seconds to $90 \%$ of full scale. The analyser also measured $\mathrm{CO}_{2}$ (range $0-10 \% \quad \mathrm{CO}_{2}$, accuracy $\pm 0.1 \%$, response time $200 \mathrm{~ms}$ to $90 \%$ of full scale), expiration flow and pressure, and exhaled volume in real time. The analyser was fitted with a biofeedback display unit to provide visual guidance for the subject to maintain the pressure and exhalation flow within a given range $\left(10 \mathrm{~cm} \mathrm{H}_{2} \mathrm{O}\right.$ and $5-61 / \mathrm{min}$ ) for end exhaled NO measurements, hence improving test repeatability and enhancing patient co-operation. ${ }^{6}$ The sampling rate through the reaction chamber of the analyser was $250 \mathrm{ml} / \mathrm{min}$. The analyser was calibrated weekly using a certified concentration of $\mathrm{NO}$ in nitrogen of $90 \mathrm{ppb}$ and $436 \mathrm{ppb}$ (BOC Special Gases, Surrey Research Park, Guildford, UK), and certified $5 \% \mathrm{CO}_{2}$ (BOC Special Gases). Ambient air NO levels were recorded prior to all measurements. NO was sampled from a side arm attached to the mouthpiece. The mean value of the last 100 measurements, acquired at $0.04 \mathrm{~s}$ intervals, was taken from the point corresponding to the plateau of end exhaled $\mathrm{CO}_{2}$ reading $\left(5-6 \% \mathrm{CO}_{2}\right)$ and representing the lower respiratory tract sample. ${ }^{6}$ Results of the analyses were computed and graphically displayed on a plot of $\mathrm{NO}$ and $\mathrm{CO}_{2}$ concentrations, pressure, and flow against time.

SUBJECTS

The portable device for the NO reservoir collection technique was tested in different groups of patients with a wide range of exhaled NO levels (1-69 ppb): 13 normal subjects (seven men) of mean (SE) age 32 (2) years, 18 adult asthmatic patients (10 men) aged 38 (8) years, 10 asthmatic children (five boys) aged 10 (5) years, 11 patients with chronic obstructive pulmonary disease (eight men) aged 56 (9) years, 16 patients with interstitial lung disease (six men) aged 55 (11) years, and five patients with primary ciliary dyskinesia (two men) aged 20 (4) years.

STUDY DESIGN

The following factors influencing exhaled NO measurements were studied: time related variations in NO content in the reservoir, soft palate closure and nasal NO contamination, dead space air contamination, influence of different expiratory flows, and collection of different volumes of exhaled air. Since our aim was to make the reservoir technique comparable with the direct measurements, NO levels measured directly and in the reservoir were compared. The reproducibility of the reservoir collection technique was also evaluated.

STATISTICAL ANALYSIS

The reproducibility of the reservoir technique and the agreement between the reservoir technique and direct method were assessed by the Bland and Altman test. ${ }^{18}$ The reproducibility of the reservoir technique was also determined as the coefficient of variation (standard deviation/ mean value $\times 100 \%) .{ }^{16}$ All data are expressed as means with $95 \%$ confidence intervals (CI). Comparisons between groups were made by non-parametric analysis. Significance was defined as a $p$ value of $<0.05$. GraphPad Prism statistical package was used.

\section{Results}

VARIATION OF NO CONCENTRATION IN THE RESERVOIR OVER TIME

Five reservoirs were filled with exhaled air (NO concentration 15 (2) ppb) and five with a test gas (60 (1) ppb). All the reservoirs contained $10 \mathrm{~g}$ silica gel. The NO concentration was tested every two hours during the daytime for two days. Exhaled and test gas NO concentrations in the reservoir were unchanged within 24 hours of collection (before 15 (2) ppb and 24 hours after 15 (2) ppb; before 60 (2) ppb and 24 hours after 60 (2) ppb, p >0.05).

SofT PALATE Closure

Expired air was collected into reservoirs from five normal volunteers whilst their nasal cavities were gently flushed (flow $21 / \mathrm{min}$ ) with a gas mixture of $4.8 \%$ argon, $15 \%$ oxygen, $4.5 \%$ carbon dioxide balanced with nitrogen. Argon was used as a tracer gas and its concentration was tested in the reservoir at the end of exhalation with a mass spectrometer (Model MGA 200, Airspec Ltd, Biggin Hill, UK, accuracy of $\pm 0.1 \%$ for argon and $\mathrm{CO}_{2}$ assessment). When flow restriction was applied concentrations of argon in the reservoir $(0.1(0.02) \%)$ were the same as those found in the ambient air (0.1 $(0.01) \%, p>0.05)$, indicating soft palate closure and therefore effective partition of the upper airways from the reminder of the respiratory tract. The argon concentration in the reservoir was significantly higher than the ambient argon concentration (4.5 (0.2), p $<0.05$, fig 2) when no flow restriction was applied.

EFFECT OF DEAD SPACE ON NO CONCENTRATION In 13 normal subjects the effect of dead space on NO concentration in the reservoir was 


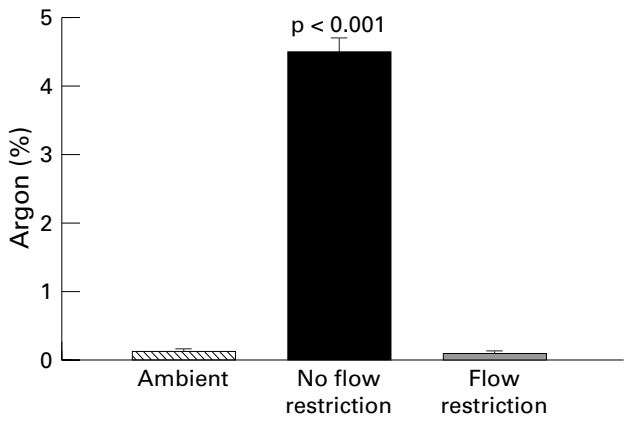

Figure 2. Mean (SE) concentration of argon in ambient air and in the exhaled air collected into the reservoir with and without flow restriction. Measurements were made while $4.8 \%$ argon was delivered to the nose at a flow rate of $2 \mathrm{l} / \mathrm{min}$ during exhalation in five normal subjects.

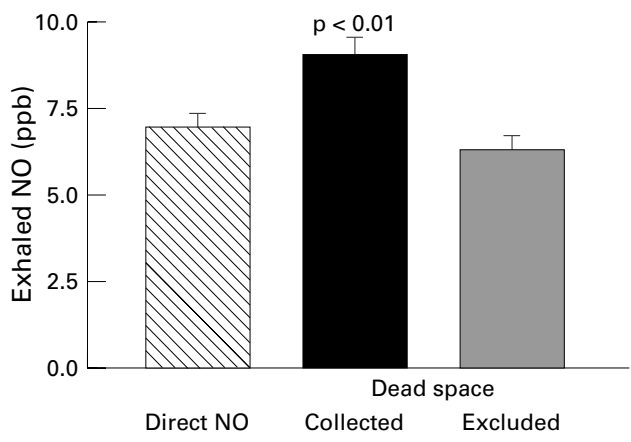

Figure 3 Mean (SE) exhaled NO levels measured by direct exhalation into a chemiluminescence analyser and collected into a reservoir with and without dead space in 13 normal subjects.

studied by excluding the first part of exhaled air using a three way valve. The time needed for washout of the dead space was estimated to be 1-2 seconds. The concentrations of NO in the reservoir were significantly higher $(9.0(0.1)$ $\mathrm{ppb})$ than when measured by the direct method (6.9 (0.1) ppb, p <0.01, $\mathrm{n}=13)$ when dead space air was not discarded. The NO values in the reservoir $(6.2(0.1) \mathrm{ppb}, \mathrm{p}>0.05, \mathrm{n}$ $=13$ ) were not different from the NO levels measured directly (fig 3 ) when dead space air was discarded (mean difference $0.4(0.08) \mathrm{ppb}$, $95 \%$ CI 0.3 to $0.5 \mathrm{ppb}$ ).

The three way valve was switched to allow exhalation in the ambient atmosphere before the end of the expiratory manoeuvre to avoid nasal contamination of exhaled breath in the reservoir at the end of exhalation due to decreasing mouth pressure.

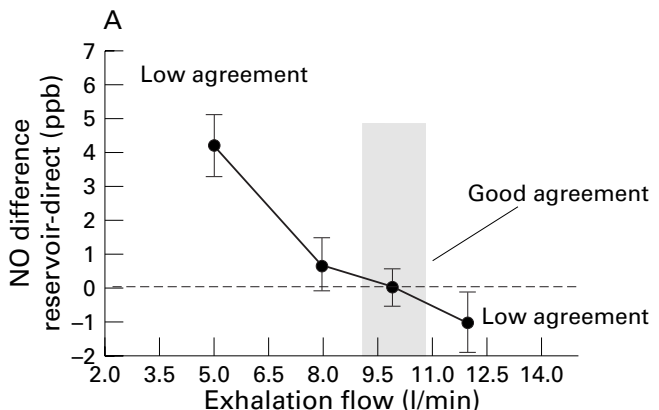

NO LEVELS IN THE RESERVOIR AT DIFFERENT EXPIRATORY FLOWS

Five normal subjects and 10 asthmatic patients were instructed to perform a complete exhalation from total lung capacity maintaining four different expiratory flows (5-6, 7-8, 10-11, and $12-13 \mathrm{l} / \mathrm{min}$ ). The NO values measured in the reservoir at different expiratory flows were compared with the direct NO measurements at a flow rate of 5-6 1/min. NO levels measured in the reservoir were markedly dependent on exhalation flow rate both in asthmatics and in healthy subjects. At an exhalation flow rate of 5-6 $1 / \mathrm{min}$ NO levels in the reservoir were significantly different from those measured directly in both normal subjects (11.0 (0.2) $\mathrm{ppb}$ and $7.3(0.5) \mathrm{ppb}$ respectively, mean difference $5.3 \mathrm{ppb}, 95 \%$ CI 5.0 to 10 , fig $4 \mathrm{~A}$ ) and those with asthma (48 (18) ppb and 17.4 (2) ppb respectively, mean difference $30 \mathrm{ppb}$, $95 \%$ CI 23 to 40 , fig 4B). At the exhalation flow rate of 7-8 $1 / \mathrm{min}$ NO levels in the reservoir were also significantly different from those measured directly in both normal subjects $(8.6$ (0.1) ppb, mean difference $1.5 \mathrm{ppb}, 95 \%$ CI 0.8 to 2 , fig $4 \mathrm{~A})$ and those with asthma $(20.3$ (12) ppb, mean difference $3 \mathrm{ppb}, 95 \%$ CI 1 to 5, fig 4B).

NO levels in the reservoir were in good agreement with the direct NO measurements at the flow rate of $10-11 \mathrm{l} / \mathrm{min}$ in both normal (7.1 (0.6) ppb, mean difference $0.2(0.05) \mathrm{ppb}$, $95 \%$ CI 0.2 to 0.3 ) and asthmatic subjects (16.9 (0.3) ppb, p >0.05, mean difference 0.3 (0.06) ppb, 95\% CI 0.2 to 0.4 ). At a higher exhalation flow rate $(12-13 \mathrm{l} / \mathrm{min})$ NO levels in the reservoir were significantly different from the direct measurements in both normal $(6.6$ (0.4) ppb, mean difference $3.3 \mathrm{ppb}, 95 \%$ CI 1 to 4$)$ and asthmatic subjects (10.1 (0.4) ppb, mean difference $7 \mathrm{ppb}, 95 \%$ CI 4 to 10 ).

\section{COLLECTION OF DIFFERENT VOLUMES OF} EXHALED AIR INTO A RESERVOIR

Ten asthmatic patients and five normal subjects were instructed to exhale into the reservoir for 10 seconds and 20 seconds at a constant flow rate $(10-11 \mathrm{l} / \mathrm{min})$. Different volumes of exhaled air were therefore collected (1.7 (0.4) 1 and $3.4(0.4)$ 1) but NO concentrations did not change either in asthmatic $(11.3$ (2.0) $\mathrm{ppb}$ and $11.2(2.0) \mathrm{ppb}$, respectively, $\mathrm{n}=$ 10 , mean difference $0.1,95 \%$ CI 0.01 to 0.2 )

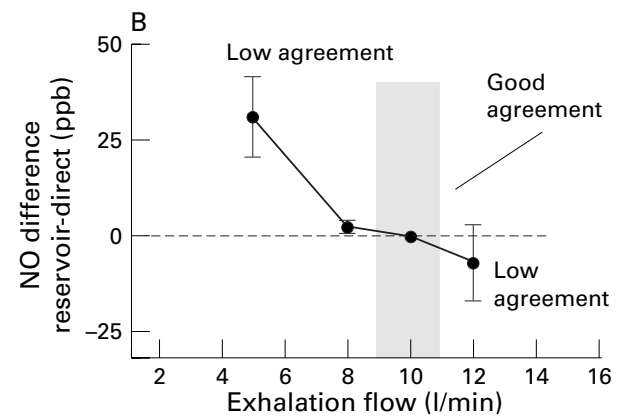

Figure 4 Mean (SE) difference in the exhaled NO levels assessed by direct measurement of NO during direct exhalation at a flow rate of 5-6 l/min and when collected into a reservoir using four different exhalation rates (5-6, 7-8, 10-11, $12-13 \mathrm{l} / \mathrm{min})$ in $(A)$ normal subjects $(n=5)$ and $(B)$ asthmatic patients $(n=10)$. Grey areas represent flow range when direct NO values were not significantly different from NO levels in the reservoir. 

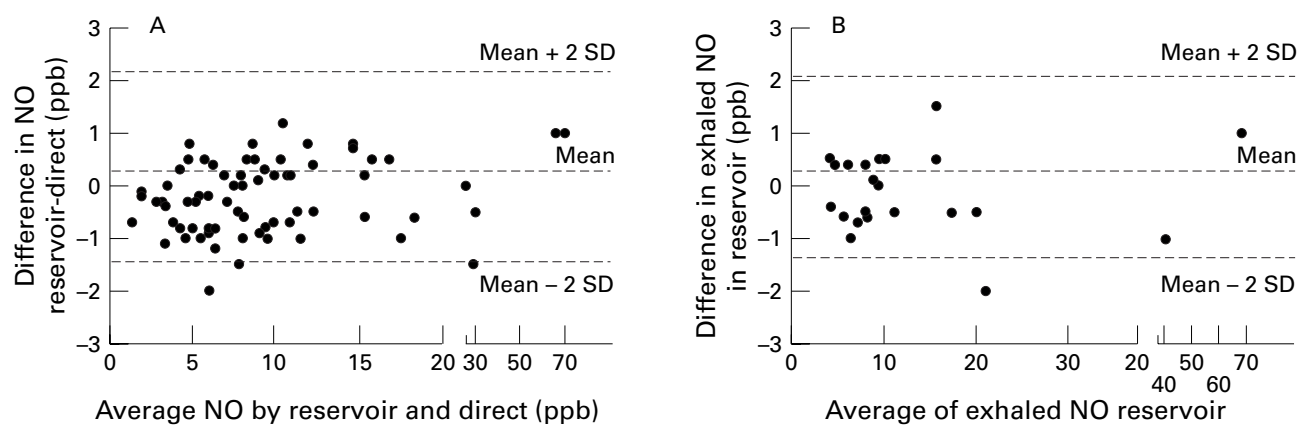

Figure 5 (A) Agreement between exhaled NO levels assessed by direct NO measurement and NO levels in the reservoir. (B) Repeatability of the reservoir method. Two exhaled NO measurements separated by five minute intervals in 13 normal and 10 asthmatic subjects.

or in normal subjects (8.8 (2.0) ppb and 9.5 (2.0) $\mathrm{ppb}$, respectively, $\mathrm{n}=5$, mean difference $0.2,95 \%$ CI 0.11 to 0.3 ).

COMPARISON OF NO LEVELS MEASURED DIRECTLY AND IN THE RESERVOIR

The agreement between exhaled NO levels determined by direct measurements and the reservoir was evaluated in 74 subjects by the Bland and Altman test. In most of the measurements the differences between the two NO values obtained by the reservoir technique and direct method were within 2SD (mean difference $-0.2(0.68) \mathrm{ppb}, \mathrm{n}=74)$ when the expiratory flow rate was $10 \mathrm{l} / \mathrm{min}$ and dead space was excluded from the collection (fig 5A).

\section{REPRODUCIBILITY OF THE RESERVOIR}

\section{COLLECTION TECHNIQUE}

The difference in exhaled NO levels measured during two successive reservoir collections made at five minute intervals plotted against their mean (single session variability) is shown in fig 5B. Most of the measurements (13 normal subjects and 10 asthmatic patients) were within $2 \mathrm{SD}$ of the mean (mean difference $0.09(0.1) \mathrm{ppb})$ with a coefficient of variation of $5.4 \%$ and $3.0 \%$ in normal and asthmatic subjects, respectively. The coefficient of variation of NO measurements made on two consecutive days (between session variability) was $6 \%$ in 13 normal subjects.

\section{Discussion}

In this study we found that the reservoir method of NO collection is reproducible and in agreement with the direct method when exhalation is pressure controlled and flow controlled, dead space air is discarded, and mouth pressure sufficient to close the soft palate is generated.

Factors influencing exhaled NO levels such as expiratory flow rates, dead space air and contamination with the nasal NO due to soft palate opening have not previously been evaluated in the reservoir collection of exhaled NO. ${ }^{7-10} 19{ }^{20}$ Thus, during tidal mouth breathing NO values in normal subjects $\left(188 \mathrm{ppb}^{20}\right)$ were higher than those obtained with a single exhalation into a reservoir $(6.2(0.4) \mathrm{ppb}) .^{7}$ The arbitrary use of different single breath manoeuvres without exhalation flow control might also explain why different $\mathrm{NO}$ values have been obtained in normal subjects $(123 \mathrm{ppb}$ and 61 ppb). ${ }^{910}$ For these reasons we developed a device for NO collection into a reservoir which allows control of expiratory flow rate and exhalation against a mild resistance with dead space discarded. This was achieved by fitting the device with a pressure gauge to enable the subject to control exhalation flow, a built in resistance, and a three way valve for dead space air elimination.

It has previously been shown that polyethylene does not affect NO levels. ${ }^{910}$ Thus no change in NO concentration ( $5 \mathrm{ppb}$ ) in a polyethylene reservoir has been demonstrated for up to 12 hours. $^{20}$ Under normal barometric pressure $(965 \mathrm{mbar})$ at a temperature of $20^{\circ} \mathrm{C}$, water and $\mathrm{CO}_{2}$ absorb $\mathrm{NO}$, a process known as "quenching". This results in $2 \%$ lower NO levels than the true levels. ${ }^{10}$ With the addition of silica gel to prevent this reaction we were also able to maintain $\mathrm{NO}$ levels unchanged for up to 24 hours.

High NO levels have been detected in the paranasal sinuse ${ }^{21}$ and nasal cavities, ${ }^{6}$ suggesting that exhaled NO may be contaminated by nasal NO. It has been shown that exhalation against a resistance prevents any nasal contamination because of soft palate closure. ${ }^{622} 23$ To evaluate possible nasal contamination of the expired air we investigated whether the nasal cavities and the pharynx were in communication during exhalation in the reservoir and therefore if the pressure generated in the mouth was adequate to close the soft palate. By applying a pressure of $10 \mathrm{~cm} \mathrm{H}_{2} \mathrm{O}$ we were able to achieve NO levels in the reservoir identical to those measured directly. This pressure was enough to close the soft palate and eliminate possible nasal contamination, as shown by the absence of argon in the reservoir when the gas was delivered continuously to the nose during an exhalation.

The concentration of NO present in the upper airways represents a mixture of ambient, nasal and tracheal NO which may influence the results unless discarded. ${ }^{5}$ Using a three way valve to discard the dead space air we demonstrated that the remaining part of exhalation was identical to the end exhaled $\mathrm{NO}$ values obtained by direct NO measurement.

It has been shown that exhaled and nasal NO are flow dependent. ${ }^{5} 1023$ The reason for NO reduction with increased expiratory flow is that the same amount of NO released is dispersed 
in a larger exhaled volume. For exhalation flows of $10 \mathrm{l} / \mathrm{min}$ the agreement between the reservoir and direct method is on the flat part of the curve (fig 4) and variations of up to $1 \mathrm{l} / \mathrm{min}$ do not influence the final NO concentration in the reservoir, reducing the influence of compliance with a steady expiratory flow. We have shown that, when expiratory flow is controlled (10-11 1/min), NO levels in the reservoir are comparable with direct measurements. It is known from Poiseuille's law that $P$ $=R \times V$ where $P=$ pressure, $R=$ resistance, and $V=$ flow). Both in the reservoir and direct method the mouth pressure is $10 \mathrm{~cm} \mathrm{H}_{2} \mathrm{O}$, therefore considering that the resistance fitted in the reservoir is lower than the direct method (bigger diameter in the reservoir, 0.5 vs 0.3 $\mathrm{cm})$, it is clear that higher flows will be needed for the reservoir $(10-11 \mathrm{l} / \mathrm{min}$ vs $5-61 / \mathrm{min}$, respectively) to provide the same mouth pressure.

The volume of exhaled air collected did not influence the NO concentration in the reservoir. Exhaled NO could therefore be collected during two or three exhalations which is particularly useful in patients with small lung volumes such as children or adults with severe restriction.

Thus, exhaled NO collected without dead space air into a reservoir during a flow and pressure controlled exhalation is a simple reproducible technique which is in good agreement with direct $\mathrm{NO}$ measurements. It allows remote NO collection and delayed NO analysis, and may be the method of choice for home monitoring of inflammatory lung diseases and epidemiological studies.

Supported by grants from IRCCS University Respiratory Hospital Milan (Italy) and the British Lung Foundation (UK).

1 Alving K, Weitzberg E, Lundberg JM, et al. Increased amount of nitric oxide in exhaled air of asthmatics. Eur amount of nitric oxide in

2 Kharitonov SA, Yates DH, Robbins RA, et al. Increased nitric oxide in exhaled air of asthmatic patients. Lance 1994;343:133-5.
3 Kharitonov SA, Barnes PJ. Exhaled NO: a new lung function test. Thorax 1996;51:233-7.

4 Lundberg JON, Weitzberg E, Lundberg JM, et al. Nitric oxide in exhaled air. Eur Respir f 1996;9:2671-80.

5 Kharitonov SA, Alving K, Barnes PJ. Exhaled and nasal nitric oxide measurements: recommendations. Eur Respir $\mathcal{F}$ 1997;7:1683-93.

6 Kharitonov SA, Chung KF, Evans DJ, et al. Increased exhaled nitric oxide in asthma is mainly derived from the lower respiratory tract. Am $f$ Respir Crit Care Med lower respiratory

7 Massaro AF, Gaston B, Kita D, et al. Expired nitric oxide levels during treatment of acute asthma. Am f Respir Crit Care Med 1995;152:800-3.

8 Borland C, Cox Y, Higenbottam T. Measurement of exhaled nitric oxide in man. Thorax 1993;48:1160-2.

9 Dillon WC, Hampl V, Schultz P, et al. Origins of breath nitric oxide in humans. Chest 1996;110:930-8.

10 Sato K, Sakamaki T, Sumino H, et al. Rate of nitric oxide release in the lung and factors influencing the concentration of exhaled nitric oxide. Am F Physiol 1996;270:L91420.

11 Maziak W, Loukides S, Culpitt S, et al. Exhaled nitric oxide in chronic obstructive pulmonary disease. Am $\mathcal{F}$ Respir Crit Care Med 1997;157:998-1002.

12 Kharitonov SA, Wells AU, O'Connor BJ, et al. Elevated levels of exhaled nitric oxide in bronchiectasis. Am $\mathcal{F}$ Respir Crit Care Med 1995;151:1889-93.

13 Lundberg JON, Nordvall SL, Weitzberg E, et al. Exhaled nitric oxide in paedriatric asthma and cystic fibrosis. Arch Dis Child 1996;75:323-6.

14 Balfour-Lynn IM, Laverty A, Dinwiddie R. Reduced upper airway nitric oxide in cystic fibrosis. Arch Dis Child 1996;75:319-22.

15 Hogman M, Stromberg S, Schedin U, et al. Nitric oxide from the human respiratory tract effectively quantified by standardised single-breath measurements. Acta Physiol Scand 1997;159:345-6.

16 Cotes JE. Lung function. Assessment and application in medicine. Fifth edition. Oxford: Blackwell Scientific Publications, 1994: 21

17 Van der Mark TW, Kort E, Meijer RJ, et al. Water vapor and carbon dioxide decrease nitric oxide readings. American Thoracic Society Conference 1997: A824.

18 Bland JM, Altman DG. Statistical methods for assessing agreement between two methods of clinical measurement. Lancet 1986;i:307-10.

19 Cremona G, Higenbottam TW, Takao M, et al. Exhaled nitric oxide in isolated pig lungs. F Appl Physiol 1995;78:5963.

20 Schilling J, Holzer P, Guggenbach M, et al. Reduced endogenous nitric oxide in the exhaled air of smokers and hypertensives. Eur Respir F 1994;74:67-71.

21 Lundberg JO, Farkas-Szallasi T, Weitzberg E, et al. High nitric oxide production in human paranasal sinuses. Nature Medicine 1995;1:370-3.

22 Kharitonov SA, Barnes PJ. Nasal contribution to exhaled nitric oxide during exhalation against resistance or during breath holding. Thorax 1997;52:540-4.

23 Silkoff PE, McClean PA, Slutsky AS, et al. Marked flow-dependence of exhaled nitric oxide using a new technique to exclude nasal nitric oxide. Am $\mathcal{F}$ Respir Crit Care Med 1997;155:260-7. 